Case Report

\title{
Usefulness of Endoscopic Managements in Patients with Ceftriaxone-Induced Pseudolithiasis Causing Biliary Obstruction
}

\author{
Yasuhiro Doi, ${ }^{1}$ Yasushi Takii, ${ }^{1}$ Hiroyuki Ito, ${ }^{1}$ Norihiko Jingu, ${ }^{1}$ Kentaro To, \\ Sinichiro Kimura, ${ }^{1}$ Koichi Kimura, ${ }^{2}$ Kensaku Sanefuji, ${ }^{2}$ Hirofumi Ikeda, ${ }^{3}$ \\ Sayaka Tachibana, ${ }^{3}$ and Takeshi Otsuka ${ }^{1}$ \\ ${ }^{1}$ Department of Internal Medicine, Munakata Medical Association Hospital, Fukuoka, Japan \\ ${ }^{2}$ Department of Surgery, Munakata Medical Association Hospital, Fukuoka, Japan \\ ${ }^{3}$ Department of Nephrology, Munakata Medical Association Hospital, Fukuoka, Japan
}

Correspondence should be addressed to Yasuhiro Doi; doiyasuhirofield@yahoo.co.jp

Received 10 July 2017; Accepted 25 September 2017; Published 2 November 2017

Academic Editor: William B. Silverman

Copyright (C) 2017 Yasuhiro Doi et al. This is an open access article distributed under the Creative Commons Attribution License, which permits unrestricted use, distribution, and reproduction in any medium, provided the original work is properly cited.

Ceftriaxone (CTRX) is known to cause reversible biliary stones/sludge, which is called biliary pseudolithiasis. We report two rare cases of biliary obstruction by pseudolithiasis shortly after completing CTRX treatment. Stones and sludge, which had not been detected before CTRX administration, appeared in the gallbladder and common bile duct and led to biliary obstruction and acute cholangitis. The obstructions were successfully treated with endoscopic retrograde biliary drainage and endoscopic sphincterotomy. CTRX-induced biliary pseudolithiasis has been reported mainly in children and adolescents but is also seen in adults with similar incidence rate. Although CTRX-induced biliary pseudolithiasis is usually asymptomatic and disappears spontaneously after discontinuing the drug, some patients develop biliary obstruction. Endoscopic managements should be considered in such cases.

\section{Introduction}

Ceftriaxone (CTRX), a widely used third-generation cephalosporin, has a broad spectrum and a long half-life of 6 to 9 hours [1]. In some cases, CTRX is known to precipitate with calcium ion in the biliary tract. The precipitation usually disappears after discontinuation of CTRX and is thus called biliary pseudolithiasis. Since the first report in 1986 [2], biliary pseudolithiasis caused by CTRX has been reported mainly in children and adolescents but also in adults $[3,4]$. Although the calcified lesions usually disappear spontaneously after discontinuation of CTRX, they sometimes cause acute cholangitis, acute cholecystitis, or acute pancreatitis, requiring interventions.

We report two cases of biliary obstruction by CTRXinduced biliary pseudolithiasis that required endoscopic managements.

\section{Case Presentation}

2.1. Case 1. A 91-year-old woman with stage 5 chronic kidney disease possibly due to hypertensive nephrosclerosis or chronic glomerulonephritis was admitted to the Department of Nephrology of our hospital because of a 2-week history of dyspnea. Physical examination on admission was not remarkable except for oxygen saturation of $91 \%$ on $2 \mathrm{~L} / \mathrm{min}$ of oxygen and pretibial pitting edema. Laboratory examinations showed white blood cell (WBC) count of $5,300 / \mu \mathrm{L}$ (reference range (RR): 3,300-8,600), C-reactive protein (CRP) $2.17 \mathrm{mg} / \mathrm{dL}$ (RR: $0-0.14$ ), blood urea nitrogen $80.3 \mathrm{mg} / \mathrm{dL}$ (RR: $8.0-20.0$ ), serum creatinine $5.69 \mathrm{mg} / \mathrm{dL}$ (RR: 0.46-0.79), aspartate aminotransferase (AST) $24 \mathrm{U} / \mathrm{L}$ (RR: 13-30), alanine aminotransferase (ALT) 9U/L (RR: 7-23), lactate dehydrogenase (LDH) $276 \mathrm{mg} / \mathrm{dL}$ (RR: $124-$ 222), alkaline phosphatase (ALP) 326 U/L (RR: 103-322), 


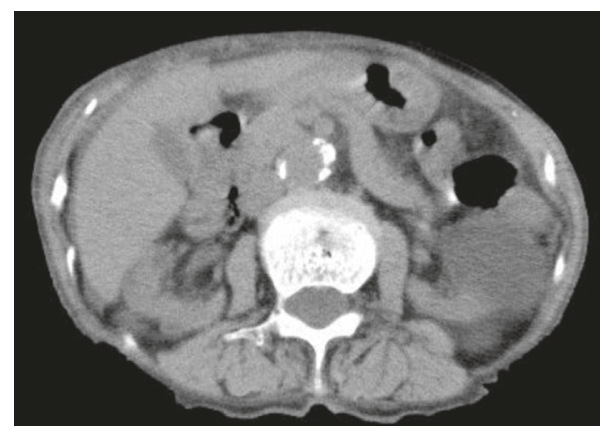

(a)
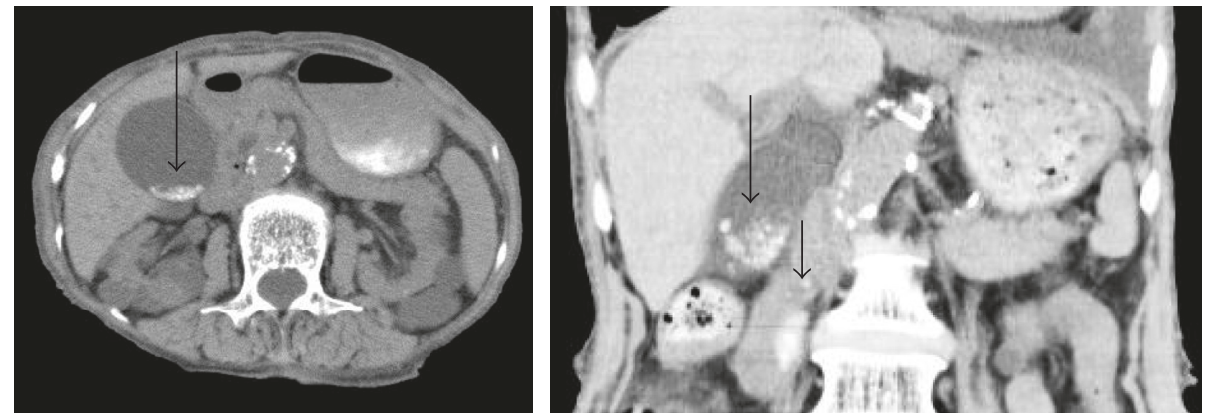

(b)

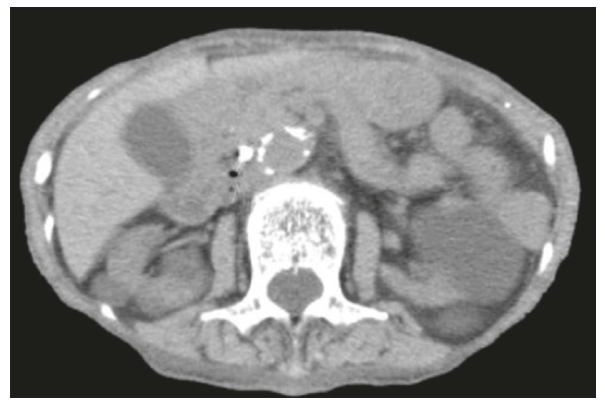

(c)

FIgURE 1: CT scans in Case 1. (a) Small stones or sludge were not detected in the biliary tract before administration of CTRX. (b) (Left, axial view; right, coronal view) small stones and sludge appeared in the gallbladder (long arrows) and common bile duct (short arrow) 3 days after ending CTRX administration. (c) The small stones and sludge disappeared after 4 weeks.

$\gamma$-glutamyl transpeptidase ( $\gamma$-GTP) 42 U/L (RR: 9-32), total bilirubin $0.6 \mathrm{mg} / \mathrm{dL}$ (RR: $0.4-1.5$ ), and serum amylase 104 U/L (RR: 44-132). Chest X-ray and computed tomography (CT) scan revealed ground-glass appearance of the bilateral lung field and consolidations of the right middle lobe and left lower lobe. The patient was diagnosed with pulmonary edema and pneumonia and was treated with $2 \mathrm{~g}$ of CTRX intravenously every 24 hours for 10 days along with intravenous furosemide. Three days after ending the administration of CTRX, she complained of right upper abdominal pain. Laboratory data demonstrated worsening of the liver function: AST $232 \mathrm{U} / \mathrm{L}$, ALT $46 \mathrm{U} / \mathrm{L}, \mathrm{LDH}$ $481 \mathrm{mg} / \mathrm{dL}$, ALP $866 \mathrm{U} / \mathrm{L}, \gamma$-GTP $167 \mathrm{U} / \mathrm{L}$, total bilirubin $0.6 \mathrm{mg} / \mathrm{dL}$, and serum amylase $115 \mathrm{U} / \mathrm{L}$. CT scan revealed small stones and sludge in the gallbladder and common bile duct, which had not been detected in the CT scan on admission (Figures 1(a) and 1(b)). A diagnosis of grade II cholangitis due to CTRX-induced biliary pseudolithiasis was made, and the patient was referred to the Department of
Internal Medicine. Endoscopic retrograde cholangiography (ERC) demonstrated the absence of bile excretion from the ampulla of Vater, indicating bile congestion by obstruction of the common bile duct (Figure 2(a)). Endoscopic retrograde biliary drainage (ERBD) by inserting a biliary stent resulted in excretion of the bile (Figure 2(b)), and cholangitis resolved after the procedure. CT scan after 4 weeks revealed disappearance of the small stones and sludge in the gallbladder and common bile duct (Figure 1(c)), and the biliary stent was withdrawn the following day.

2.2. Case 2. An 82-year-old woman visited the hospital because of diarrhea and mild abdominal pain in the umbilical region. She had a medical history of dermatomyositis, interstitial pneumonitis, diabetes mellitus, and chronic heart failure with diastolic dysfunction and a relatively low left ventricular ejection fraction of $50 \%$ and was receiving $9 \mathrm{mg}$ of prednisolone and $2 \mathrm{mg}$ of tacrolimus. A diagnosis of acute 


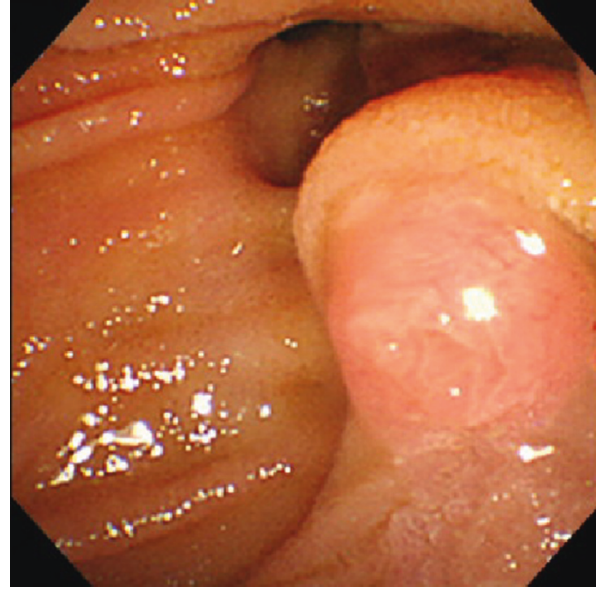

(a)

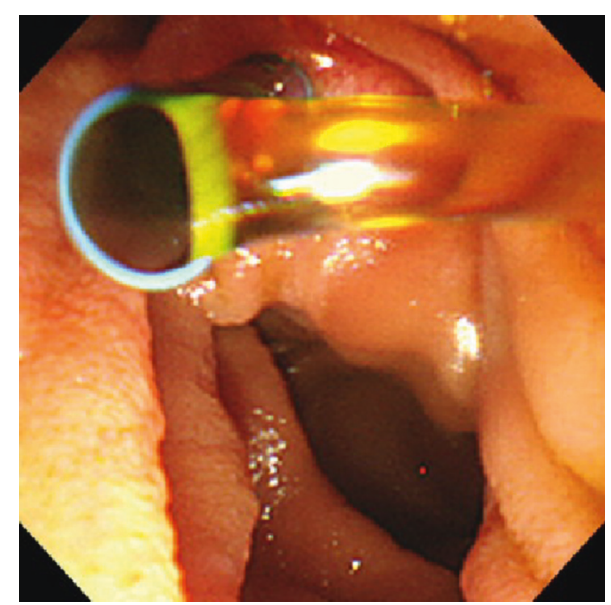

(b)

FIGURE 2: Endoscopic views before (a) and after (b) ERBD in Case 1. (a) Absence of bile excretion from the ampulla of Vater indicated bile congestion by common bile duct obstruction. (b) Insertion of biliary stent resulted in excretion of the bile.

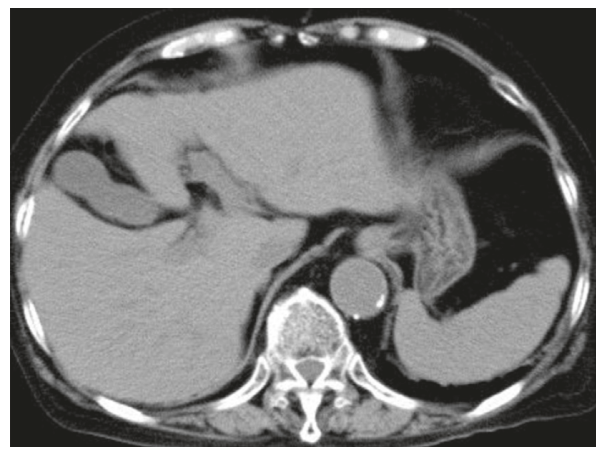

(a)
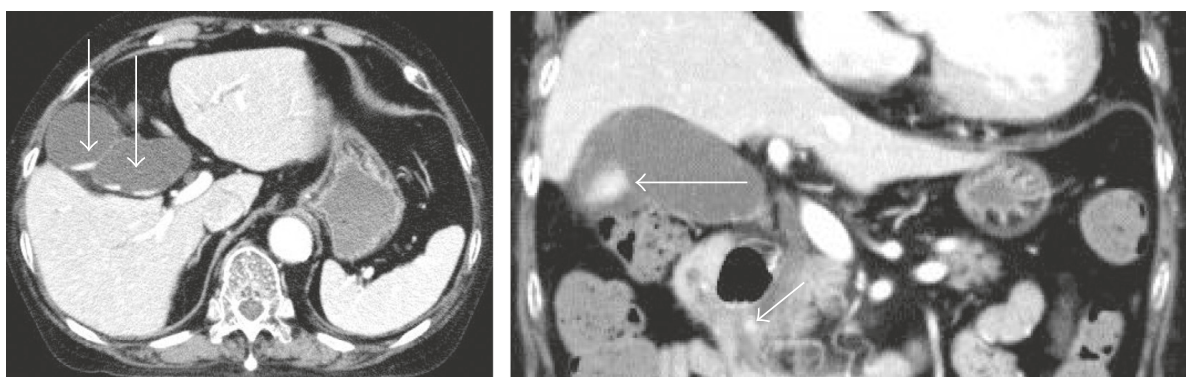

(b)

Figure 3: CT scans in Case 2. (a) Small stones or sludge were not detected in the biliary tract before administration of CTRX. (b) (Left, axial view; right, coronal view) small stones and sludge appeared in the gallbladder (long arrows) and common bile duct (short arrow) 10 days after ending CTRX administration.

enteritis was made. In addition to fasting and intravenous hydration, she was treated with $2 \mathrm{~g}$ of intravenous CTRX every 24 hours for 5 days, and subsequently with oral levofloxacin at $500 \mathrm{mg}$ once daily for 5 days after campylobacter had been cultured from the stool obtained on admission. She recovered fully and was discharged on day 13. Two days after discharge, she complained of severe upper abdominal pain and back pain. Laboratory data showed leukocytosis (WBC count $14,000 / \mu \mathrm{L})$, elevation of CRP $(1.42 \mathrm{mg} / \mathrm{dL})$, mild liver dysfunction (AST 47 U/L, ALT 18 U/L, LDH $235 \mathrm{U} / \mathrm{L}$, ALP
$233 \mathrm{U} / \mathrm{L}, \gamma$-GTP $73 \mathrm{U} / \mathrm{L}$, total bilirubin $0.5 \mathrm{mg} / \mathrm{dL}$ ), and elevations of serum amylase (938 U/L) and lipase (4113 U/L, RR: 12-52). CT scan revealed small stones and sludge in the gallbladder and common bile duct, which had not been detected two weeks earlier (Figure 3). She was diagnosed with grade II acute cholangitis and grade 1 acute pancreatitis. Emergent ERC showed deposition of white sludge on the ampulla of Vater and absence of bile excretion (Figure 4(a)). Endoscopic sphincterotomy (EST) and ERBD were performed, resulting in excretion of the bile (Figure 4(b)) and 


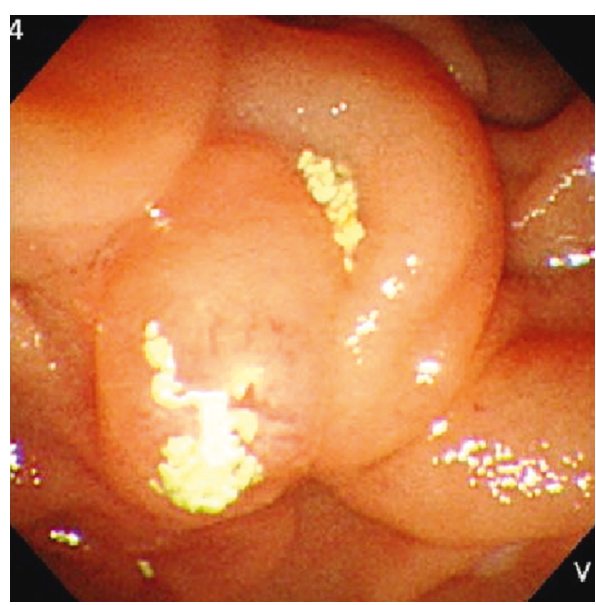

(a)

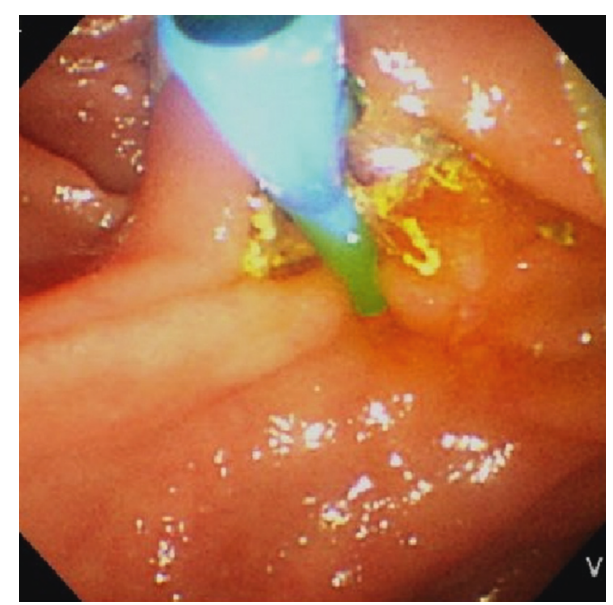

(b)

FIgUre 4: Endoscopic views before (a) and after (b) EST and ERBD in Case 2. (a) Deposition of white sludge and absence of bile excretion were seen on the ampulla of Vater. (b) EST and ERBD led to excretion of the bile.

resolution of the abdominal pain. Hydration required for the treatment of acute pancreatitis exacerbated the heart failure, making the treatment of acute pancreatitis difficult. The patient developed multiple organ failure and died on day 17.

\section{Discussion}

We experienced two cases of common bile duct stones and sludge causing acute cholangitis shortly after completing CTRX treatment, which required endoscopic managements. Acute pancreatitis was also seen in Case 2. In both cases, biliary stones or sludge had not been detected in the CT scan 2 weeks before the onset. In Case 1, the stones and sludge spontaneously disappeared 4 weeks later. The white fine precipitation observed in Case 2 was different from the appearance of ordinary biliary stones consisting mainly of cholesterol or bilirubin. These observations strongly indicated that CTRX induced the biliary stones and sludge. Previous studies demonstrated that intravenously administered CTRX is excreted to the bile as a divalent anion and can precipitate with calcium ion to form calcium-CTRX complex at a dose of $2 \mathrm{~g}$ or higher [1,5-8].

Cases of pseudolithiasis have been reported mainly in children and adolescents with an incidence of $17-57 \%$ after CTRX administration [9-14]. In most cases, biliary pseudolithiasis was detected between 3 and 14 days after initiating CTRX administration and completely resolved within a few weeks after discontinuing CTRX. Biliary symptoms, such as right upper abdominal pain, nausea, and vomiting, were reported in $0-20 \%$ of these cases. Although the CTRXinduced biliary pseudolithiasis is less well studied in adults, the clinical features including the incidence rate are similar to those for children and adolescents $[4,15,16]$.

Interventional procedures are required in some cases of CTRX-induced biliary pseudolithiasis when the stones or sludge induce biliary obstruction, leading to acute cholangitis or acute pancreatitis as in our cases [7, 17-20]. Endoscopic procedures, such as EST and/or ERBD, are the treatment of choice in such cases because they are less invasive than surgical procedures. Most of the previous reports performed surgery [7, 17-19], and there is only one case report in the English literature which reported endoscopic management for CTRX-induced biliary pseudolithiasis [20]. Because discontinuation of CTRX usually leads to spontaneous resolution of biliary pseudolithiasis, we believe that cholecystectomy should be considered only when biliary obstruction persists even after discontinuing the drug and endoscopic managements are difficult. This point is supported by a case of an 18-month-old boy with CTRXinduced cholecystitis, where stones in the gallbladder detected during CTRX administration were not found in the gallbladder resected 9 days after discontinuing the drug [21].

\section{Conclusion}

CTRX-induced biliary pseudolithiasis is usually asymptomatic and disappears spontaneously after discontinuation of the drug, making the complication easily overlooked especially in adults. However, some patients develop biliary obstruction requiring emergent procedures, and thus caution is necessary during CTRX administration. Once biliary obstruction occurs, endoscopic managements such as EST and ERBD should be considered.

\section{Conflicts of Interest}

The authors declare that they have no conflicts of interest.

\section{References}

[1] D. M. Richards, R. C. Heel, R. N. Brogden, T. M. Speight, and G. S. Avery, "Ceftriaxone. A review of its antibacterial activity, pharmacological properties and therapeutic use," Drugs, vol. 27, no. 6, pp. 469-527, 1984.

[2] U. B. Schaad, H. Tschäppeler, and M. J. Lentze, "Transient formation of precipitations in the gallbladder associated with 
ceftriaxone therapy," Pediatric Infectious Disease, vol. 5, no. 6, pp. 708-710, 1986.

[3] R. H. Meyboom, H. Kuiper, and A. Jansen, "Ceftriaxone and reversible cholelithiasis,” BMJ, vol. 297, no. 6652, p. 858, 1988.

[4] C. Pigrau, A. Pahissa, S. Gropper, D. Sureda, and J. M. Martinez Vazquez, "Ceftriaxone-associated biliary pseudolithiasis in adults," Lancet, vol. 334, no. 8655, p. 165, 1989.

[5] J. M. Brogard, J. F. Blickle, F. Jehl, J. P. Arnaud, D. ParisBockel, and H. Monteil, "High biliary elimination of ceftriaxone in man," International Journal of Clinical Pharmacology, Therapy, and Toxicology, vol. 26, no. 4, pp. 167-172, 1988.

[6] H. Z. Park, S. P. Lee, and A. L. Schy, "Ceftriaxone-associated gallbladder sludge. Identification of calcium-ceftriaxone salt as a major component of gallbladder precipitate," Gastroenterology, vol. 100, no. 6, pp. 1665-1670, 1991.

[7] A. J. Lopez, P. O'Keefe, M. Morrissey, and J. Pickleman, "Ceftriaxone-induced cholelithiasis," Annals of Internal Medicine, vol. 115, no. 9, pp. 712-714, 1991.

[8] M. L. Shiffman, F. B. Keith, and E. W. Moore, "Pathogenesis of ceftriaxone-associated biliary sludge. In vitro studies of calcium-ceftriaxone binding and solubility," Gastroenterology, vol. 99, no. 6, pp. 1772-1778, 1990.

[9] U. B. Schaad, J. Wedgwood-Krucko, and H. Tschaeppeler, "Reversible ceftriaxone-associated biliary pseudolithiasis in children," Lancet, vol. 332, no. 8625, pp. 1411-1413, 1988.

[10] A. Ozturk, M. Kaya, D. Zeyrek, E. Ozturk, N. Kat, and S. Z. Ziylan, "Ultrasonographic findings in ceftriaxone: associated biliary sludge and pseudolithiasis in children," Acta Radiologica, vol. 46, no. 1, pp. 112-116, 2005.

[11] B. Biner, N. Öner, C. Çeltik et al., "Ceftriaxone-associated biliary pseudolithiasis in children," Journal of Clinical Ultrasound, vol. 34, no. 5, pp. 217-222, 2006.

[12] A. Soysal, K. Eraşov, I. Akpinar, and M. Bakir, "Biliary precipitation during ceftriaxone therapy: frequency and risk factors," Turkish Journal of Pediatrics, vol. 49, no. 4, pp. 404-407, 2007.

[13] A. Palanduz, I. Yalçin, E. Tonguç et al., "Sonographic assessment of ceftriaxone-associated biliary pseudolithiasis in children," Journal of Clinical Ultrasound, vol. 28, no. 4, pp. 166-168, 2000.

[14] S. Murata, T. Aomatsu, A. Yoden, and H. Tamai, "Fasting and bed rest, even for a relatively short period, are risk factors for ceftriaxone-associated pseudolitiasis," Pediatrics International, vol. 57, no. 5, pp. 942-946, 2015.

[15] K. L. Heim-Duthoy, E. M. Caperton, R. Pollock, G. R. Matzke, D. Enthoven, and P. K. Peterson, "Apparent biliary pseudolithiasis during ceftriaxone therapy," Antimicrobial Agents and Chemotherapy, vol. 34, no. 6, pp. 1146-1149, 1990.

[16] K. Dohmen, A. Yamamoto, H. Tanaka, M. Haruno, and S. Shimoda, "An elderly case of ceftriaxone-associated pseudolithiasis that developed during therapy for acute pneumonia," Kanzo, vol. 57, no. 2, pp. 106-112, 2016.

[17] F. M. Robertson, T. M. Crombleholme, S. E. Barlow, M. Verhave, and D. Brown, "Ceftriaxone choledocholithiasis,” Pediatrics, vol. 98, no. 1, pp. 133-135, 1996.

[18] M. C. Maranan, S. I. Gerber, and G. G. Miller, "Gallstone pancreatitis caused by ceftriaxone," Pediatric Infectious Disease Journal, vol. 17, no. 7, pp. 662-663, 1998.

[19] G. Famularo, S. Polchi, and C. De Simone, "Acute cholecystitis and pancreatitis in a patient with biliary sludge associated with the use of ceftriaxone: a rare but potentially severe complication," Annali Italiani di Medicina Interna, vol. 14, no. 3, pp. 202-204, 1999.
[20] E. Lebovics, M. S. Halata, J. A. Rosario, J. Lantin, S. M. Schwarz, and W. S. Rosenthal, "Endoscopic management of ceftriaxone pseudolithiasis involving the common bile duct and gallbladder," Gastrointestinal Endoscopy, vol. 40, no. 2, pp. 246-248, 1994.

[21] C. Blais and R. Duperval, "Biliary pseudolithiasis in a child associated with 2 days of ceftriaxone therapy," Pediatric Radiology, vol. 24, no. 3, pp. 218-219, 1994. 


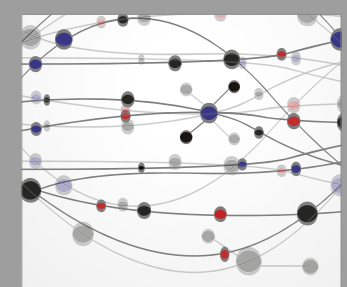

The Scientific World Journal
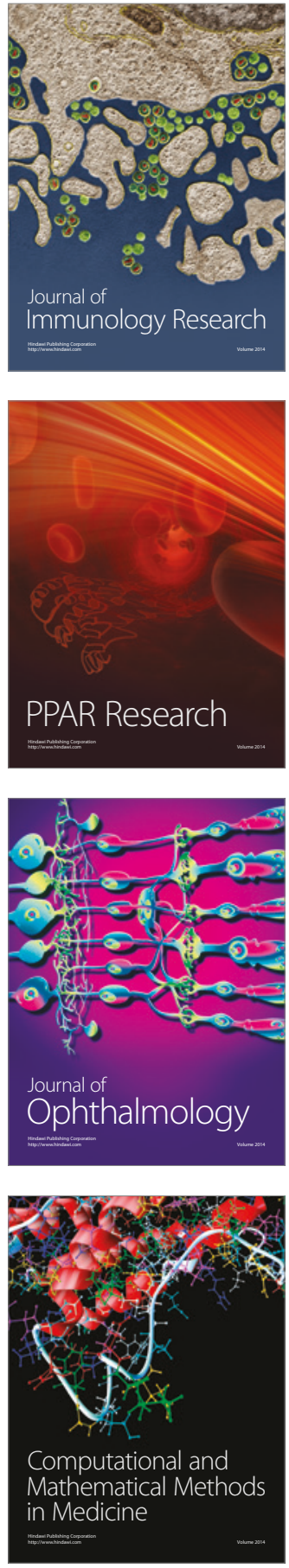

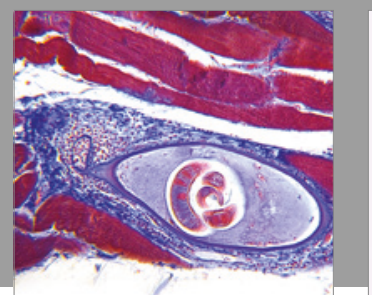

Gastroenterology Research and Practice
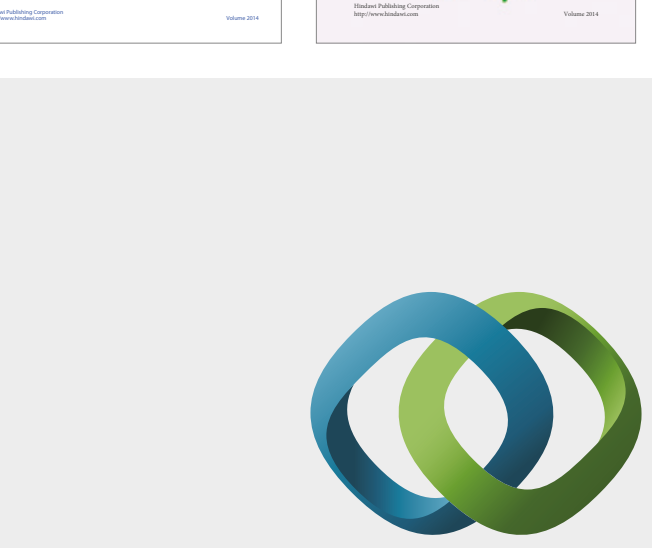

\section{Hindawi}

Submit your manuscripts at

https://www.hindawi.com
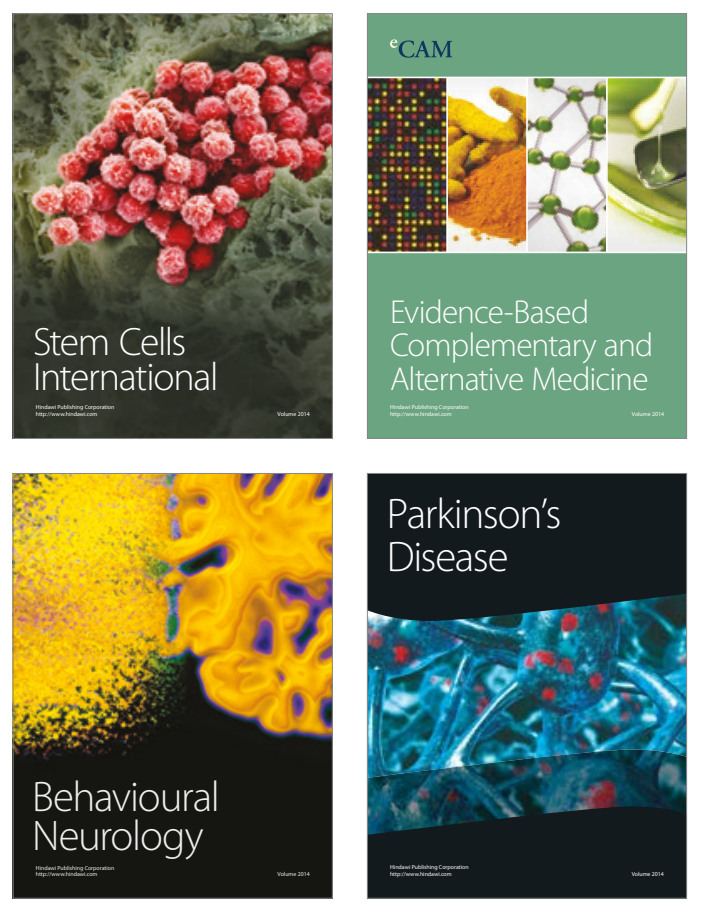
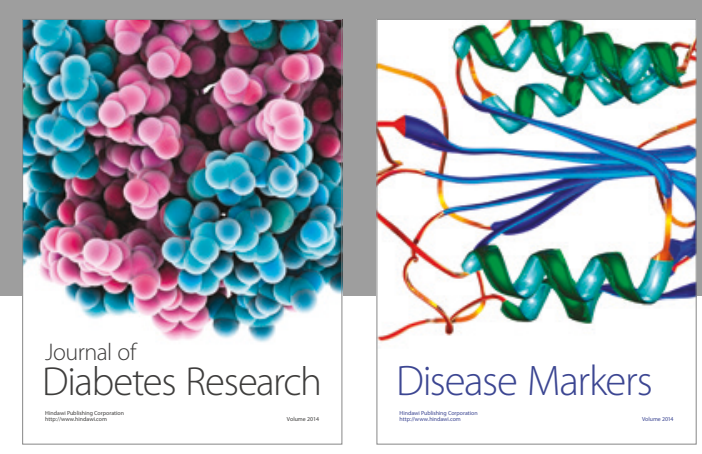

Disease Markers
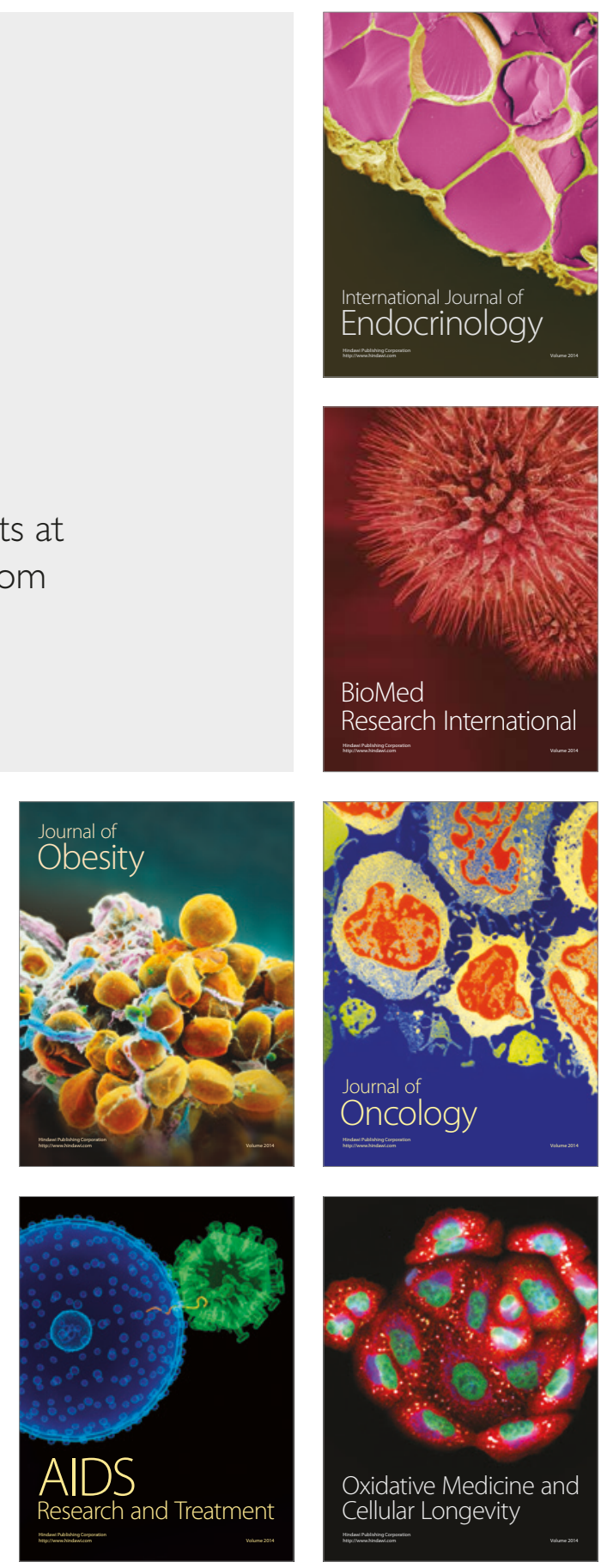